\title{
CONTRIBUIÇÕES DA ECOLOGIA POLÍTICA PARA A DESCONSTRUÇÃO DE NARRATIVAS VINCULADAS A INJUSTIÇAS AMBIENTAIS
}

Luciano Zanetti Pessôa Candiotto ${ }^{1}$

\begin{abstract}
Resumo: Pesquisadores ligados à Ecologia Política têm evidenciado, analisado e lutado contra injustiças ambientais. Permeando essas injustiças, existem diversos tipos de narrativas que contribuem para sua ocultação ou relativização. Nesse sentido, este artigo discorre sobre a pertinência de se identificar e de se buscar desconstruir narrativas enviesadas, que têm minimizado ou até justificado injustiças ambientais, e, ao mesmo tempo, de se fortalecer a construção e replicação de outras narrativas, que fundamentem a importância da luta por justiça ambiental. Para tanto, a metodologia utilizada foi fundamentada em leituras de autores adeptos do vasto e multidisciplinar campo de conhecimento da Ecologia Política, sobretudo da Ecologia Política latino-americana, além de vivências e reflexões do autor, enquanto pesquisador e cidadão. Argumenta-se que, da mesma forma em que se faz necessário "desconstruir" determinadas narrativas que apoiam e sustentam injustiças, é preciso, também, identificar, conhecer, analisar e fortalecer o processo de "construção" de alternativas que contribuam para a justiça ambiental e para novas relações entre seres humanos e, deles, com a natureza, incluindo narrativas, ações de resistência e de demonstração a respeito da viabilidade de se materializar tais alternativas no plano concreto, bem como no imaginário/percepção das pessoas.
\end{abstract}

Palavras-chave: Justiça Ambiental. Desconstrução. Construção. América Latina. Colonialidade.

\section{POLITICAL ECOLOGY CONTRIBUTIONS FOR DECONSTRUCTION OF NARRATIVES LINKED TO ENVIRONMENTAL INJUSTICES}

\begin{abstract}
Researchers linked to Political Ecology have highlighted, analyzed and fought against environmental injustices. Permeating these injustices, there are several types of narratives that contribute to their concealment or relativization. In this sense, this article discusses the pertinence of identifying and seeking to deconstruct biased narratives, which have minimized or even justified environmental injustices, and, at the same time, to strengthen the construction and replication of other narratives, which substantiate the importance the fight for environmental justice. To this end, the methodology used was based on readings by authors adept in the vast and multidisciplinary field of knowledge of Political Ecology, especially of Latin American Political Ecology, in addition to the author's experiences and reflections, as a researcher and citizen. It is argued that, just as it is necessary to "deconstruct" certain narratives that support and sustain injustices, it is also necessary to identify, know, analyse and strengthen the process of "building" alternatives that contribute to environmental justice and for new relationships between human beings and, with them, with nature, including narratives, actions of resistance and demonstration regarding the feasibility of materializing such alternatives in the concrete plane, as well as in the imagination / perception of people.
\end{abstract}

\footnotetext{
${ }^{1}$ Universidade Estadual do Oeste do Paraná (UNIOESTE), Geografia, Francisco Beltrão, Brasil, luciano.candiotto@unioeste.br, https://orcid.org/0000-0003-4162-7144
} 
Keywords: Environmental Justice. Deconstruction. Construction. Latin America. Coloniality.

\section{CONTRIBUCIONES DE LA ECOLOGÍA POLÍTICA PARA LA DESCONSTRUCCIÓN DE NARRATIVAS VINCULADAS A INJUSTICIAS AMBIENTALES}

Resumen: Los investigadores vinculados a la ecología política han destacado, analizado y luchado contra las injusticias ambientales. Permeando estas injusticias, hay varios tipos de narrativas que contribuyen a su ocultamiento o relativización. En este sentido, este artículo discute la pertinencia de identificar y tratar de deconstruir narrativas sesgadas, que han minimizado o incluso justificado las injusticias ambientales, y, al mismo tiempo, fortalecer la construcción y replicación de otras narrativas, que corroboran la importancia La lucha por la justicia ambiental. Para este fin, la metodología utilizada se basó en lecturas de autores expertos en el vasto y multidisciplinario campo de conocimiento de Ecología Política, especialmente de Ecología Política Latinoamericana, además de las experiencias y reflexiones del autor, como investigador y ciudadano. Se argumenta que, así como es necesario "deconstruir" ciertas narrativas que apoyan y sostienen las injusticias, también es necesario identificar, conocer, analizar y fortalecer el proceso de "construir" alternativas que contribuyan a la justicia ambiental y para nuevas relaciones entre los seres humanos y, con ellos, con la naturaleza, incluyendo narrativas, acciones de resistencia y demostración con respecto a la viabilidad de materializar tales alternativas en el plano concreto, así como en la imaginación / percepción de las personas.

Palabras clave: Justicia Ambiental. Deconstrucción. Construcción. America Latina. Colonialidad.

\section{Introdução}

$\mathrm{Na}$ busca por problematizar a contribuição da Ecologia Política na desconstrução de narrativas que minimizam, ocultam e, até, justificam injustiças ambientais, bem como na construção de narrativas emancipatórias e descoloniais, fundamentadas em experiências empíricas que fortaleçam a luta por justiça ambiental $^{2}$, este artigo foi elaborado. Seu conteúdo procura apresentar alguns fundamentos da Ecologia Política, com ênfase na Ecologia Política latino-americana, que, além de valorizar a simbiose entre conhecimentos acadêmicos e populares, possui algumas especificidades epistemológicas, relacionadas a processos históricos de rapina ambiental, apropriação de territórios, exploração de seus povos e, consequentemente, da geração e manutenção de desigualdades sociais latentes. Os fundamentos da Ecologia Política latino-americana partem de críticas à

\footnotetext{
2 Partindo do princípio proposto por SOUZA (2019), de que o termo ambiental já carrega consigo a dimensão social, optou-se por utilizar o termo injustiça ambiental. No entanto, a referência ao termo ambiental sempre envolverá, necessariamente, a sociedade. Portanto, entende-se que, no conceito de ambiente, natureza e sociedade estão embutidas e se relacionam de forma dialética.
} 
Colonialidade (QUIJANO, 2005) e, desde o século XXI, têm se fortalecido através do debate sobre a Modernidade/Colonialidade (ESCOBAR, 2005; 2011; ALIMONDA, 2011; 2015; 2017; PORTO-GONÇALVES, 2006; ROMERO, 2016) e, consequentemente, com base na perspectiva do denominado giro decolonial (ROMERO, 2016; ALIMONDA, 2017; MACHADO ARAOZ, 2017).

A metodologia utilizada, abrangeu, sobretudo, revisão bibliográfica e sistematização de reflexões sobre possíveis formas de se contribuir, enquanto pesquisador e/ou ativista, em processos de desconstrução de narrativas, que, de alguma forma, relativizam injustiças ambientais, bem como na proposição e construção de narrativas e ações/práticas vinculadas ao debate sobre descolonialidade (decolonialidad). As proposições apresentadas, dizem respeito a atuação de pesquisadores e, de forma mais tímida, de extensionistas e ativistas.

A principal argumentação do artigo se encontra na defesa de que há uma relação dialética entre desconstrução e construção ${ }^{3}$, de modo que a desconstrução de injustiças e de narrativas que as relativizam, leva ao questionamento sobre quais seriam as alternativas possíveis. Com base em Enrique Leff (2017), são discutidos elementos deste processo dialético de desconstrução e construção no âmbito da Ecologia Política, que envolvem o plano material (construção de experiências e ações concretas) e simbólico (construção de narrativas pautadas em um imaginário sobre a possibilidade de um futuro sustentável e de outros mundos).

A construção de narrativas e de ações que fortaleçam a luta por justiça ambiental (ACSELRAD, 2010; ROMERO, 2016; MERLINSKY, 2017) justifica-se pela existência de injustiças e desigualdades sociais, bem como por um processo histórico de rapina ambiental (SOUZA, 2013), fundamentado em uma economia de rapina (ALIMONDA, 2011).

Ao denunciar ações de exploração, intolerância, violação de direitos e degradação ambiental, faz-se necessário divulgar suas causas e consequências. Ao

\footnotetext{
${ }^{3}$ Cabe ressaltar, já no início do artigo, o que se entende por desconstrução e por construção. A palavra construção, significa "ação de construir, de dar forma a"; "reunião das ações e atividades a partir das quais algo é construído". No sentido figurado, "processo através do qual algo é elaborado". Já a palavra desconstrução, significa o antônimo de construção. No seu sentido figurado, é "desfazer o que está construído". (DICIONÁRIO AURÉLIO, on line. <https://www.dicio.com.br/aurelio/>). Desta forma, a desconstrução e a construção propostas neste artigo, dizem respeito: 1) ao processo de desconstrução de injustiças ambientais e, sobretudo, de narrativas que ocultam, minimizam ou apoiam tais injustiças; 2) ao processo de construção de justiça ambiental e de alternativas decoloniais (ou anti coloniais - SOUZA, 2019), com destaque para narrativas que contribuam para fortalecer a justiça ambiental e as alternativas decoloniais, insurgentes e/ou emancipatórias, que se contrapõem ao paradigma da modernidade/colonialidade (e do próprio desenvolvimento). Portanto, faz-se necessário esclarecer também, que tanto as injustiças ambientais quanto as narrativas que as apoiam, se manifestam tanto no plano material quanto no simbólico.
} 
mesmo tempo, surgem e se concretizam propostas alternativas de ação, que podem ser entendidas como contra-racionalidades (SANTOS, 1996), insurgências (SOUZA, 2013; 2017) e iniciativas fundamentadas no pós-desenvolvimento ${ }^{4}$. Tais propostas, no contexto latino-americano, têm se apontado sob um viés decolonial, que parte da crítica ao projeto colonial europeu e à sua propagação discursiva e psicológica dos ideais de Modernidade, civilização, progresso e desenvolvimento.

Assim, entende-se que as injustiças ambientais/territoriais, e suas narrativas, precisam ser evidenciadas e devidamente desconstruídas, por meio de narrativas insurgentes e emancipatórias, que contribuam para despertar a indignação das pessoas, sobretudo em relação às narrativas conservadoras e preconceituosas que têm se fortalecido no atual momento histórico de desinformação, fake news, distorção e ocultação de evidências empíricas e científicas. Por sua vez, a construção de narrativas e ações que fortaleçam a justiça ambiental, requer reflexão, ação e divulgação, na busca por ampliar a sensibilização social a respeito da relevância de mudanças estruturais na relação entre sociedade e natureza, bem como na relação entre os seres humanos. Tal desafio, implica em um processo de expansão de informações, conhecimentos, princípios e ações, que precisam ser socialmente debatidos e continuamente revisados, através da interação com os afetados pelas injustiças ambientais, e de sua visibilização perante outros sujeitos sociais.

\section{A Ecologia Política para além do ambientalismo}

Inicialmente, é mister destacar que, apesar da Ecologia Política ser considerada uma das correntes do ambientalismo/ecologismo, esse ramo do conhecimento pressupõe que a ecologia e o ambiente são muito mais do que o "mundo natural" dos preservacionistas. De modo geral, o ambientalismo caracterizase como um amplo e heterogêneo movimento de defesa da natureza e do ambiente ecologicamente equilibrado. Sua heterogeneidade se dá em virtude de diversas correntes de interpretação sobre as causas e consequências da crise ou problemática denominada ambiental.

\footnotetext{
${ }^{4}$ A obra "Pluriverse: a post-development dictionary", organizada por Kothari et al. (2019), relaciona diversas perspectivas alternativas ao desenvolvimento, incluindo a justiça ambiental, a ecologia social, a autonomia, a democracia ecológica radical, o ecofeminismo, o ecosocialismo, 0 ecoanarquismo, o bem-viver, entre outras possibilidades que têm sido debatidas no âmbito da Ecologia Política e da crítica ao desenvolvimento.
} 
Martinez-Alier (2015a, p. 38-39) destaca as três principais correntes que envolvem o ambientalismo/ecologismo: 1) O "culto à vida selvagem", baseado simplesmente na preservação da natureza silvestre, acrítico ao crescimento econômico e preocupado somente com o crescimento populacional; 2) O "credo da ecoeficiência", preocupado com o manejo sustentável ou prudente dos recursos naturais e com o controle da contaminação, através de novas tecnologias pautadas na modernização ecológica; 3) O movimento pela justiça ambiental e o ecologismo dos pobres, preocupados com diversos tipos de conflitos ambientais oriundos do crescimento econômico e da desigualdade social, da escala local à global.

Apesar da Ecologia Política estar diretamente associada à terceira corrente mencionada, entende-se que ela vai além do ambientalismo, pelo fato de estar fundamentada no questionamento das relações estabelecidas entre sociedade e natureza no contexto do produtivismo e, sobretudo, do capitalismo, mas, principalmente, por preocupar-se com um amplo processo de transformação ontológica (LEFF, 2017), que, necessariamente, envolve, de forma integrada, o natural (biológico, ecológico) e o social (cultural, político, econômico).

Ao entender que a Ecologia Política parte da premissa de que a relação entre sociedade e natureza é construída socialmente, as relações de poder entre os seres humanos são preponderantes no processo de concepção, utilização e degradação do ambiente (RAFFESTIN, 1993; SOUZA, 2019a). A Ecologia Política se apresenta, portanto, como ramo de conhecimento multidisciplinar, apesar de algumas áreas, como a Geografia, a Antropologia (BATTERBURY, 2015; MARTINEZ-ALIER, 2015a) e a História ambiental (ALIMONDA, 2011), se destacarem.

Enquanto termos como preservação ambiental, desenvolvimento sustentável, ecoeficiência, capitalismo ecológico, marketing ecológico, economia verde, entre outros, têm sido propagados no âmbito das duas primeiras correntes apresentadas por Martinez-Alier (2015a), na Ecologia Política, esses termos costumam ser problematizados e rechaçados (ESCOBAR, 2005; PORTO-GONÇALVES, 2006). Por outro lado, a crise ecológico-civilizatória, marcada por um processo material e simbólico de mercantilização da natureza, bem como por imaginários e narrativas de naturalização de catástrofes, são evidências do que se tem denominado Capitaloceno 5 (MACHADO ARAOZ, 2017). 
Desta forma, considerando que os movimentos e correntes denominados ambientalistas são heterogêneos e, muitas vezes, contraditórios, a Ecologia Política tem-se diferenciado das demais correntes, por partir do pressuposto de que os problemas ambientais são, sobretudo, sociais, e que, por serem problemas sociais, são também, eminentemente políticos/territoriais, pois estão amplamente vinculados às relações de poder (ALIMONDA, 2017; SOUZA, 2019a, 2019b).

Por mais que existam processos naturogênicos ${ }^{6}$ que a humanidade não consegue controlar, a concentração da riqueza, do poder político e econômico; o produtivismo; o consumismo; o individualismo e a competição, são elementos fundamentais para se analisar e apreender os problemas ambientais (que englobam a dimensão natural e social de forma integrada). Portanto, para além da discussão sobre a magnitude da influência humana nas alterações de processos naturais, interessa à Ecologia Política, desvendar a dimensão política da questão ecológica e ambiental, cujo objeto central de interpretação e análise se encontra na relação sociedade-natureza. Para Batterbury (2015), a função da Ecologia Política é explicar como e porque os humanos têm transformado a natureza.

\section{Origens da Ecologia Política}

Apesar da expressão "Ecologia Política" ser utilizada desde o final da década de 1950, autores como Bailey e Bryant (2005), Martinez-Alier (2015a), Batterbury (2015) e Souza (2018), entendem que foi a partir da década de 1980, especificamente nos anos 1990, que a ecologia política se expandiu. Inicialmente, a expansão se deu na academia, mas as lutas sociais por justiça ambiental (ACSELRAD, 2010; MERLINSKY, 2017; MARTINEZ-ALIER, 2019) e por um ecologismo popular e dos pobres (MARTINEZ-ALIER, 2015a) ampliaram o escopo da ecologia política para além da academia, incorporando, sobretudo, ativismos.

[...] a Ecologia Política admite ser entendida como um campo de conhecimento interdisciplinar que lida com os processos de transformação material da natureza e produção de discursos sobre ela e seus usos, procurando realçar as relações de poder subjacentes a esses processos (agentes, interesses, classes e grupos sociais, conflitos etc.), em marcos histórico-geográfico-culturais concretos e específicos. Não obstante, a Ecologia Política não se resume a um conhecimento de tipo acadêmicouniversitário. [...] a Ecologia Política sempre foi, também, um saber com um

proceso de (in)civilización ha ido haciendo de lo humano una especie extremadamente peligrosa: peligrosamente insensible ante el dolor, el sufrimiento y la devastación de la Vida" (MACHADO ARAOZ, 2017, p. 196).

${ }^{6}$ Em virtude dos termos natureza e natural serem objeto de amplas discussões filosóficas, optou-se, com base em Souza $(2015 ; 2019 a)$, por utilizar o termo naturogênico, como referência ao fato de se tratar de fenômenos com gênese natural, independente da existência ou ação humana. 
forte lado ativista, ou de compromisso com a práxis. (SOUZA, 2018, p. 299300).

A Ecologia Política considera um hibridismo entre o teórico e o empírico (BLAIKIE, 1989). Nesse sentido, entende-se que ela pode abarcar interpretações oriundas da academia acerca da relação sociedade-natureza, considerando: 1) aspectos teóricos sobre visões de natureza e de evolução humana e social; 2) a análise de lutas, injustiças e conflitos ambientais, que podem partir de movimentos ativistas ou mesmo de eventos em que as lutas não são evidentes. $O$ aporte acadêmico às injustiças e às lutas ambientais contribui, portanto, para compreender e interpretar esses fenômenos, bem como para evidenciar questões que, muitas vezes, podem estar ocultas. Por outro lado, os ativismos ambientais nutrem as pesquisas da Ecologia Política.

Na visão de Harvey (1993), os argumentos ecológicos nunca são socialmente neutros, da mesma forma que os argumentos sociopolíticos também não são ecologicamente neutros. Há, então, relação dialética entre a dimensão ecológica e a dimensão política e econômica em qualquer projeto, de modo que as abordagens ecológicas e ambientais devem considerar essa inter-relação entre ecologia e política.

Como o acesso aos recursos naturais é sempre mediado socialmente, a Ecologia Política envolve múltiplos processos, que, por sua vez, atuam em diferentes escalas (BATERBURRY, 2015). Segundo Martinez-Alier (2015b, p. 57), "lo local y lo global van juntos".

Um dos fundamentos da Ecologia Política se encontra na abertura da academia e dos intelectuais ao diálogo de saberes com indígenas, pobres e outras populações excluídas e expropriadas de seus territórios (desterritorializadas). A Ecologia Política se assume enquanto um campo de conhecimento (e de ação), intimamente relacionado ao pensamento crítico e ao esforço social para a construção de ecologias dos saberes (SOUZA SANTOS, 2018).

Ao entender que a Ecologia Política analisa conflitos relacionados à distribuição desigual de recursos naturais, assim como de problemas ambientais, que se manifestam enquanto consequências do modelo de desenvolvimento, que é desigual e produtivista, Martinez-Alier (2015a) clama por um ecologismo dos pobres. 


\section{Ecologia Política do Sul e a Ecologia Política Latino-americana}

Apesar da Ecologia Política ser um campo de conhecimento acadêmico comum a pesquisadores no Norte e do Sul global, existe uma diferenciação relevante entre a Ecologia Política anglófona, ou seja, proveniente de países onde se iniciou o debate sobre a dimensão política das questões ecológicas e ambientais, e a Ecologia Política que tem sido debatida no Sul global, sobretudo na América Latina. Esse tema, tem sido tratado por autores como Escobar (2011), Leff (2017), Alimonda (2017), Moreano, Molina e Bryant (2017), permeando um amplo debate acerca de uma Ecologia Política global, que, ao mesmo tempo, considere que há uma pluralidade de situações empíricas que ocorrem em nível local, regional e nacional, tornando pertinente (e necessária) a aceitação da existência de diferenças (ESCOBAR, 2011).

Mesmo com essa perspectiva de coalisão entre os ecologistas políticos, existe, no contexto do pensamento intelectual dos países do Norte global, uma ênfase na análise, de modo que alguns autores, rechaçam o envolvimento de intelectuais em movimentos ativistas e na militância voltada à ação direta entre os ecologistas políticos. Para Bryant e Bailey (2005), a maior contribuição dos ecologistas políticos se encontra na descrição e compreensão dos problemas e, não necessariamente, na prescrição de soluções. Nesse sentido, esses autores entendem que não cabe aos pesquisadores da Ecologia Política, se envolver em ativismos e na luta por mudanças. Basta que eles identifiquem e analisem os problemas ambientais, que, certamente, estão relacionadas a situações de injustiça social.

Apesar de mencionarem a necessidade de mudanças radicais no plano das relações de poder, os britânicos Bryant e Bailey adotam postura, muito comum no meio acadêmico ocidental, sobretudo norte-americano e europeu, de limitar o papel dos pesquisadores e intelectuais ao plano analítico. Contudo, isso tem sido problematizado por pesquisadores ligados à Ecologia Política na América Latina, sobretudo por aqueles que criticam o mundo moderno-colonial (PORTOGONÇALVES, 2006) e a colonialidade do saber, propondo, assim, amplo processo de descolonialidade no pensamento e nas ações.

Machado Araoz (2017), afirma que a Ecologia Política do Sul emerge como um processo de reflexão-ação, como uma ciência contra-hegemônica e como uma promotora do diálogo de saberes. Este diálogo, é nutrido "[...] a partir de las propias luchas de re-existencia de los pueblos y sujetos expropiados", sendo "[...] condición 
y efecto de la mundialización e intensificación del metabolismo necroeconómico del Capital" (p. 212).

Segundo Leff (2017, p. 143), a "[...] ecología se vuelve política a través de las relaciones de poder que vienen a transformar la dinámica ecológica decurrente de la generatividad de la physis y el devenir de la naturaleza. La raíz política de este proceso histórico es ontológica y epistemológica".

[...] los procesos de resistencia a la invasión de la modernidad sobre los mundos de vida tradicionales se convierten en movimientos de rexistencia; son la expresión de otras ontologías existenciales que se manifiestan en la arena política. La restauración de la ontología de la vida reclama una reflexión del pensamiento sobre la vida que no es solamente un giro teórico. Se trata de una reapropiación cultural de la naturaleza que se produce en un terreno político, en el campo estratégico del poder. Las luchas socioambientales son la manifestación de una voluntad de poder vivir [...] (LEFF, 2017, p. 143-144).

As lutas ambientais mencionadas por Leff (2017), são, necessariamente, lutas contra injustiças ambientais. Estas, têm fundamentado o debate sobre justiça ambiental. Ao mencionar o processo histórico de saque de recursos naturais de países do Sul por países do Norte, que ditam e comandam a ideologia ocidental moderno-colonial e que importam recursos e exportam rejeitos, Martinez-Alier (2015a) ressalta que o ecologismo dos pobres é um movimento de luta por justiça ambiental, de modo que há uma ligação entre justiça ambiental e ciência participativa.

Esse movimento de luta por justiça ambiental, também é objeto de estudo da argentina Gabriela Melinsky (2017), a qual faz uma análise de movimentos de luta por justiça ambiental na América Latina, evidenciando cinco teses a respeito das estratégias adotadas: 1) a importância dos territórios nas lutas ambientais (inscripción territorial); 2) a defesa de bens comuns de povos expropriados; 3) a produção de conhecimentos coletivos populares; 4) a deliberação através de assembleias populares ambientais; e 5) a demanda por reconhecimento das lutas populares, por parte de instituições oficiais.

A Ecologia Política tem crescido na América Latina, ao mesmo tempo que intelectuais e ativistas latino-americanos têm contribuído para seu avanço epistemológico, teórico-metodológico e empírico. Os cinco séculos de colonização europeia, marcados por um amplo processo de apropriação de ecossistemas para obtenção de recursos naturais, oriundos de solos, minérios, fauna, flora e águas, e, consequentemente, da exploração de seus povos originários (indígenas de várias etnias), fazem parte das raízes do que atualmente se denomina América Latina 
[ALIMONDA (2011, 2015; 2016; 2017); LEFF (2015; 2017); PORTO-GONÇALVES e LEFF (2015); ALIMONDA, PÉREZ e MARTÍN (2017a; 2017b)]. Essa história também exerceu influência sobre as ciências sociais e sobre a Ecologia Política latinoamericana, de modo que o pensamento crítico e o questionamento da colonialidade, da modernidade e do desenvolvimento, são aspectos marcantes. "[...] el trauma catastrófico de la conquista y la integración en posición subordinada, colonial, en el sistema internacional, como reverso necesario y oculto de la modernidad, es la marca de origen de lo latinoamericano" (ALIMONDA, 2011, p. 21).

Segundo Leff (2015), a América Latina é a região mais importante na história e no desenvolvimento da Ecologia Política, por ser um terreno fértil de pensamento sobre como as relações e poder influenciam processos de desterritorialização e reterritorialização, moldando paisagens e lugares de vida das pessoas. Essas relações estão ligadas às dimensões política, econômica, ecológica e cultural, o que faz com que as realidades da América Latina despertem 0 interesse de pesquisadores da Região e de fora dela. Por outro lado, o pensamento epistemológico e ontológico no contexto das ciências humanas e sociais na América Latina tem sido construído a partir de ampla crítica ao pensamento ocidental e eurocêntrico, que exerce forte influência sobre a relação material estabelecida com a natureza (decorrentes da colonialidade), mas, também, sobre as representações sociais da população latino-americana, ou seja, ao imaginário, amplamente ancorado nos ideais de modernidade e desenvolvimento. A busca por processos de emancipação humana é latente em boa parte do pensamento intelectual latinoamericano.

En la ecología política latinoamericana late una reflexión que nace de la emancipación de la colonialidad del conocimiento, de una conexión más directa y estrecha sobre las formas de comprensión de los pueblos sujetos a los efectos del poder; que emerge por la cercanía de los procesos de degradación ecológica y los conflictos ambientales, de su pertenencia a su historia, sus culturas y sus paisajes [...] (LEFF, 2017, p. 146).

Na América Latina, a Ecologia Política possui uma relação próxima com os ativismos, explícita ou implicitamente de cunho ambiental, sendo caracterizada como:

[...] una elaboración político-intelectual de vanguardia, que intenta con angustia responder a los tremendos desafíos que la época presenta para los pueblos de nuestro continente, reconociendo la necesidad ineludible de criticar los presupuestos civilizatorios de la modernidad y del desarrollo convencionales. (ALIMONDA, 2017, p. 43).

Tanto Leff $(2015,2017)$ quanto Alimonda $(2011,2015 ; 2016$; 2017) enfatizam o papel da Ecologia Política no questionamento da colonialidade e na anunciação do 
chamado giro decolonial. Para Alimonda (2015), esse é um diferencial em relação às Ecologias Políticas dos países centrais, pois há reconhecimento de que nossa história é diferente, havendo uma realidade geo-histórica comum entre os países latino-americanos. Portanto, a história ambiental de exploração da América Latina conduz ao questionamento do eurocentrismo e da Modernidade/Colonialidade, reforçando a pertinência da busca por identidade própria, a partir da indagação sobre nosso passado.

Romero (2016) alerta para não se confundir colonialidade com colonialismo, haja vista que "[...] la dominación sufrida por los pueblos originarios en Latinoamérica no terminó con el fin del colonialismo" (p. 16). A colonialidade ainda é exercida através de uma matriz de poder pautada na dominação desses povos. Segundo ela, existem três tipos de colonialidade:

1) A colonialidade do poder - que se dá através da legitimação do poder e da riqueza por uma parte da população branca;

2) A colonialidade do saber - que instaura uma racionalidade tecno-científica como única forma válida de conhecimento, ocultando outras formas de conhecimento ou de "epistemes" (conhecimento indígena, por exemplo);

3) A colonialidade do ser - alusiva à produção de uma subjetividade dos indivíduos, que privilegia um modo de ser eurocêntrico, patriarcal e branco, menosprezando e ocultando outros modos de ser (indígena, mulher, negro etc.).

Essas três dimensões da colonialidade possuem forte relação com os planos material e imaginário nos países e na sociedade que compõem o que se denomina América Latina. A exploração branca de povos originários e de seus territórios, levou à produção de um substrato espacial material ${ }^{7}$ colonizado, e, consequentemente, ao predomínio de uma racionalidade técnico-científica e de um imaginário colonial. Portanto, faz-se necessário desconstruir as narrativas que justificam essa colonialidade e as injustiças ambientais decorrentes deste processo histórico, que se mantém até hoje.

Para Leff (2015), como o foco da Ecologia Política está nas relações de poder, que são relações desiguais, a América Latina está envolta em processos de subordinação a outros países, bem como às elites dos países da região. $\mathrm{Na}$ Ecologia Política latino-americana, os preceitos de justiça socioecológica (ambiental) e de emancipação social estão baseados na busca por autonomia política e pela

\footnotetext{
${ }^{7}$ Souza (2013).
} 
reapropriação social-cultural da natureza, através de resistências populares acerca da manutenção de seus territórios e territorialidades.

Ao evidenciar e questionar a existência de um amplo processo de colonialidade, que é econômica, política e cultural na América Latina, Leff (2015, 2017) enfatiza a importância atual do pensamento descolonial, que se baseia na descolonização do conhecimento, e que leva ao questionamento de ideias eurocêntricas, desde a antiga filosofia grega à moderna ciência e tecnologia ocidental, responsáveis pela conquista, colonização e inserção na globalização, de sociedades e culturas latino-americanas tradicionais. Esse processo requer subversão sistemática das formas de pensar, das práticas produtivas e dos modos de vida - como aqueles dos grupos indígenas - que foram menosprezados e considerados antítese ao progresso e à modernidade. Assim, Leff (2015) clama pela necessidade de desconstrução de uma realidade construída pela racionalidade econômica, científica e tecnológica moderna, bem como pelo reconhecimento e reavaliação de sistemas de conhecimento tradicionais e distintos do sistema atualmente dominante. Para tanto, seria preciso repensar as relações entre o real e o simbólico, no sentido de permitir que as pessoas possam construir outros futuros.

\section{Dialética de desconstrução-construção de narrativas e de práticas de (in)justiça ambiental, a partir da Ecologia Política}

Com base no pensamento de Enrique Leff $(2015$; 2017) a respeito da Ecologia Política latino-americana e de diversas menções que este autor faz aos termos desconstrução, construção e reconstrução, bem como no debate sobre justiça ambiental no contexto da Ecologia Política, a sequência do artigo é dedicada à apresentação de algumas reflexões a respeito de um olhar dialético sobre processos de desconstrução de injustiças ambientais, com foco nas narrativas que, de alguma forma, relativizam injustiças ambientais, ocultando, minimizando, justificando e, até, apoiando tais injustiças, por um lado; e de construção de narrativas e práticas insurgentes, emancipatórias e descoloniais, que contribuam para a justiça ambiental.

De forma similar ao pensamento de Alimonda (2015), Souza (1988), ao discorrer sobre a dialética sócio-espacial, ressalta a existência de uma relação dialética entre o material e o imaginário. Ao propor, neste artigo, uma dialética da desconstrução-construção de injustiças e justiças ambientais, atribuindo ênfase aos 
discursos/narrativas, bem como às práticas/ações, evidencia-se a ideia de amálgama entre o simbólico e o concreto.

O processo de desconstrução, se dá, principalmente, no imaginário das pessoas, através da aceitação e incorporação de discursos, valores e representações sociais, que são de suma importância na legitimação da dimensão material/concreta, ou seja, na aceitação ou naturalização da concentração do poder e da riqueza; da degradação ambiental; das relações sociais desiguais; da desterritorialização de populações; e da própria lógica técnica, científica e políticoideológica do capitalismo.

Conforme alerta de Machado Araoz (2017, p. 196), "más peligroso y más grave que la propia destructividad del capitalismo, es su capacidad para moldear subjetividades cuyas estructuras perceptivas, sensoriales y cognitivas resultan completamente incapaces de sentir el deterioro objetivo de las fuentes y procesos de vida $[\ldots] "$.

Desta forma, as narrativas, que muitas vezes não são fundamentadas em evidências científicas e empíricas, são de suma importância para a manutenção e expansão de injustiças ambientais.

\section{Injustiças ambientais e as lutas por justiça ambiental}

Apesar de o conceito de justiça ambiental ter destaque na Ecologia Política, não há justiça em contextos onde predominam ou existem injustiças. A luta por justiça ambiental se dá, portanto, para superar injustiças ou para garantir direitos conquistados socialmente. Em um mundo repleto de injustiças ambientais, violação de direitos e relações desiguais de poder, as lutas por justiça ambiental são as mais variadas. Todavia, as injustiças ambientais atingem, majoritariamente, os pobres e marginalizados.

A noção de justiça ambiental exprime um movimento de ressignificação da questão ambiental, pois, entrelaçada com as tradicionais questões sociais, a população de baixa renda serve de arena para a alocação dos rejeitos e entulhos (lixões, aterros etc.) resultantes da exploração intensa dos recursos naturais. Assim, há um processo de desigualdade ambiental, ou seja, uma exposição daqueles que são socialmente mais desprovidos aos riscos ambientais (ACSELRAD, 2010).

"La justicia ambiental se manifiesta en los derechos para reconstruir mundos de vida y diseñar futuros posibles, trascendiendo el propósito de internalizar los costos 
ecológicos y de distribuir los beneficios y potenciales de la naturaleza” (LEFF, 2017, p. 144).

No Brasil, as populações mais pobres são submetidas aos custos ambientais do desenvolvimento, geralmente direcionados para locais próximos de suas moradias. Com a ausência de políticas ambientais de licenciamento e fiscalização de atividades apropriadas e sem políticas sociais e de emprego consistentes, essas populações ficam suscetíveis a locais poluentes e perigosos. As lutas por justiça ambiental, além de proporem a interrupção dos mecanismos de transferência dos custos ambientais do desenvolvimento para os mais pobres, incluem a defesa dos direitos a ambientes culturalmente específicos; a defesa dos direitos a proteção ambiental equânime contra a segregação socioterritorial e a desigualdade ambiental promovidas pelo mercado; a defesa dos direitos de acesso equânime aos recursos ambientais, contra a concentração das terras férteis, das águas e do solo seguro nas mãos dos interesses econômicos dos mais ricos; e a defesa dos direitos das populações futuras (ACSELRAD, 2010).

Considerando que a injustiça social e a degradação ambiental têm a mesma raiz, haveria que se alterar o modo de distribuição - desigual - de poder sobre os recursos ambientais e retirar dos poderosos a capacidade de transferir os custos ambientais do desenvolvimento para os mais despossuídos. (ACSELRAD, 2010, p. 109).

\section{Diferentes tipos de injustiças ambientais}

A partir da consideração de que existem diferentes tipos de injustiças ambientais, busca-se aqui, evidenciar que algumas injustiças, que não necessariamente são percebidas enquanto algo nefasto ou intencional, seja pela sociedade em geral, seja, inclusive, por parte de alguns indivíduos de populações afetadas. As injustiças ambientais que geram lutas populares e conflitos ideológicos por territórios e recursos, podendo também gerar conflitos e opressão física, têm sido objeto de estudo de vários pesquisadores da Ecologia Política. No entanto, existem outros tipos de injustiça ambiental, que podem não estar explícitos e aparentes, seja para a sociedade, seja para os afetados e ativistas, bem como para os próprios pesquisadores, mas que podem ser objeto de estudos por parte de pesquisadores ligados à Ecologia Política.

Conforme apontado por Gómez (2015, p. 102), com base no pensamento de Arturo Escobar, existe uma ordem discursiva fundamentada na ideologia do desenvolvimento, "que establece quién habla a nombre de él, desde qué perspectiva 
lo hace, con qué peso argumentativo y a través de qué clasificaciones". Tal ordem, influencia subjetividades e representações sociais (percepções) sobre o espaço geográfico por parte dos indivíduos, incluindo a natureza, a economia, a política e o ambiente, de modo que grupos e sujeitos com maior poder político e econômico, acabam tendo condições mais adequadas para coagir ou oprimir pessoas em relação a determinados discursos e narrativas, ocultando ou distorcendo evidências empíricas e científicas.

A existência de injustiças ambientais é algo complexo, pois as relações de poder são variadas e, muitas vezes, difíceis de se identificar e de se apreender integralmente. Conforme apontado por Raffestin (1993), existe o Poder visível, institucionalizado, hierárquico; e existe o poder invisível, que, muitas vezes, não se manifesta enquanto um poder institucionalizado ou instituído, mas que se dá nas mais variadas relações sociais, geralmente, de forma implícita. Bachrach e Baratz (2011[1962]) chamam a atenção para o fato de o poder não se refletir somente em relações ou tomadas de decisões concretas, pois existem elementos incomensuráveis no âmbito do poder, de modo que a aparição de alguns assuntos ou conflitos, contrastada com o ocultamento de outros, já é, por si, um exercício de poder.

Como o objetivo deste artigo está na reflexão sobre injustiças ambientais e na discussão sobre a desconstrução dessas injustiças, perpassando o plano das narrativas (simbólico/imaginário) e o plano material (lutas por territórios, recursos naturais e condições de sobrevivência) de forma dialética, a proposta de diferenciar alguns tipos de injustiças ambientais parte do pressuposto de que o poder é multidimensional e de que os sujeitos injustiçados não podem ser culpabilizados por aspectos que podem estar relacionados a algum tipo de conformismo ou de acomodação. Se existe conformismo ou acomodação, as causas e origens explicitas e incomensuráveis - destes processos, requerem uma avaliação detalhada. A história dos sujeitos, suas condições de acesso à educação, seu ambiente familiar, seus direitos e sua exploração, precisam ser levados em consideração para que seja possível entender a forma como cada indivíduo se posiciona ou age a determinadas situações de injustiça ambiental. Ademais, existem relações de poder entre os sujeitos afetados pelas injustiças ambientais, de forma institucionalizada, ou não.

Desta forma, há também, um processo dialético entre os valores de um indivíduo (princípios éticos, crenças etc.) e a influência de sujeitos externos e de 
suas ações (opressão física e moral, apropriação territorial, desterritorialização, violência etc.), na percepção de cada indivíduo. Isso, certamente, condiciona a visão sobre injustiças ambientais, levando a algumas situações possíveis, elencadas a seguir:

1) Injustiças explícitas e aparentes, geradoras de mobilização e/ou e conflitos

Esse tipo de injustiça tem sido o mais abordado em pesquisas da Ecologia Política (ESCOBAR, 2011; MERLINSKY, 2017; SVAMPA, 2013; e outros capítulos dos livros organizados por ALIMONDA, PÉREZ e MARTíN, 2017a e 2017b), pois a indignação dos afetados acaba gerando mobilizações, reivindicações e conflitos com os responsáveis por determinada injustiça. Geralmente, as mobilizações e os conflitos se dão quando a injustiça ocorreu (dano ambiental; despejo de pessoas de determinados lugares - processos de desterritorialização; instalação de algum tipo de atividade poluidora ou geradora de impactos ambientais), haja vista que as pessoas já foram, de alguma forma, afetadas por ela. Existem, porém, mobilizações e conflitos que se iniciam antes da implantação de uma obra ou projeto, a partir do momento em que há organização social para questionar e tentar barrá-lo. Essas mobilizações e conflitos podem ocorrer quando as pessoas afetadas passam a ter conhecimento do projeto; em audiências públicas para discutir Estudos de Impacto Ambiental e Relatórios de Impacto Ambiental (EIA/RIMA), por exemplo; ou no início da construção de determinada obra ou projeto.

A palavra explícita, se refere a uma injustiça que é, de alguma forma, visível para os afetados e a população do entorno onde ocorre determinada injustiça. A existência de resíduos no ar ou em águas, alterações na paisagem (desmatamento, rompimento de barragem, mortandade de peixes ou outros animais, represamento de áreas) ou nos próprios corpos das pessoas (como problemas de pele e outros traços fisicamente evidentes), são elementos que tornam uma ação geradora de injustiça em algo explícito.

Já o termo aparente, diz respeito a divulgação de determinada injustiça pela imprensa ou mídia (local, regional ou nacional). Quando há essa divulgação, a injustiça é popularizada para a maior parte da população, e acaba chamando a atenção das pessoas que não são diretamente afetadas, podendo fazer com que elas também se mobilizem de alguma forma, seja através de redes sociais, seja através de alguma ação direta ou ativismo. 
Nesse tipo de injustiça, um grupo de indivíduos, ao perceber determinada situação enquanto uma injustiça, pelo fato de ser afetado por ela, ou seja, de sentir seus efeitos/consequências, passa a se organizar coletivamente para identificar a origem da injustiça e para lutar contra ela. Essa luta, que se dá por meio de reivindicações e, geralmente se inicia a partir da busca de um processo de diálogo, pode ir avançando em direção a outras estratégias de ação. Inicialmente, busca-se adotar os procedimentos legais e institucionais. Porém, em casos onde não há acordos ou há negligência, difamação e, até criminalização das reivindicações e dos movimentos sociais por parte dos responsáveis pela injustiça ou mesmo de apoiadores desses responsáveis, podem ser utilizadas estratégias insurgentes, de contraposição a "ordem" estabelecida pelo status quo.

Souza (2017, p. 389-390), denomina as estratégias adotadas pelos movimentos sociais, como práticas sociais insurgentes, afirmando que elas podem ser: 1) violentas ou não violentas; b) duráveis ou efêmeras; c) imediatamente políticas ou imediatamente culturais; d) ruidosas ou silenciosas; e) abertas ou (às) escondidas; f) local ou supralocal (e, às vezes, trasnacional).

2) Injustiças explícitas e aparentes, mas que não geram mobilizações e/ou conflitos

Nesse caso, apesar de determinada injustiça ambiental ser sentida pelos afetados; estar visível na paisagem ou em corpos humanos ou animais; ser conhecida pela população do entorno (e de outros lugares); ser alvo de divulgação pela mídia, através de notícias na imprensa, mídia ou outras formas de divulgação e comunicação; o grupo afetado não consegue se organizar para gerar algum tipo de mobilização social que sensibilize o poder público a agir ou que incomode o responsável por tal injustiça.

Nessas situações, o indivíduo ou todo o grupo afetado, pode perceber a injustiça; sofrer consequências dela; conhecer sua origem, mas não se mobilizar para lutar contra ela, por entender que, apesar de se tratar de uma injustiça e de um problema, não é possível mudar a situação, justamente pelo fato da necessidade de embates com grupos ou sujeitos com maior poder sócio-político ou econômico. Podem existir casos onde indivíduos ou todo o grupo afetado perceba a injustiça, pelo fato de sofrer suas consequências. Todavia, por não conhecer a origem da ação que leva a injustiça; por não saber a quem recorrer; ou mesmo por entender 
que não se possui força para mudar a situação, não se chega a um processo de mobilização/luta.

Nesse contexto, também é comum a existência de discursos oficiais e tendenciosos por parte do Estado e/ou de grupos empresariais, por exemplo, evidenciando os possíveis aspectos "positivos" de determinada obra, projeto ou atividade. O responsável pela ação que leva à injustiça ou mesmo o Estado, pode se utilizar de um discurso de que a ação geradora da injustiça se trata de algo necessário, mesmo que seja um "mal necessário", e que os efeitos negativos serão, de alguma forma, compensados ou minimizados. Diversos tipos de empreendimentos podem ser instalados sob esse argumento.

$\mathrm{Na}$ tentativa de exemplificar esse tipo de situação, pode-se mencionar algum caso de contaminação de água, de desmatamento ou de queimada, que afeta determinado grupo social mas que, pelo fato de ser algo corriqueiro, pode passar a ser naturalizado, não desencadeando algum tipo de mobilização da população afetada, de modo que pode acabar ficando impune por parte de órgãos de fiscalização e mesmo do poder judiciário. Também podem existir casos onde a população se mobiliza, mas a falta de resultados efetivos acaba desanimando o grupo, que pode passar a deixar de lutar contra a injustiça. A falta de atuação do Estado (principalmente do poder executivo e judiciário) acaba podendo enfraquecer diversas mobilizações e lutas de pobres e explorados.

3) Injustiças explícitas e relativamente ocultadas, não geradoras de mobilizações e/ou conflitos

Apesar da injustiça ser explícita para aqueles que são diretamente afetados por ela, o fato de a injustiça não ser divulgada, pode contribuir para sua ocultação para a maior parte da sociedade, mesmo àquela residente no entorno. Além disso, o elemento já mencionado, atinente ao fato de não se acreditar que é possível vencer uma luta contra sujeitos poderosos ou de não se ter apoio social a respeito do problema, pode inibir a população afetada a se mobilizar.

Outra situação, mais grave ainda, pode ocorrer quando indivíduos ou um grupo social diretamente afetado por uma injustiça não a percebe enquanto tal, apesar de sentir seus efeitos negativos e de ter conhecimento da própria divulgação do problema por veículos da imprensa, mesmo que essa divulgação se dê sobre situações ocorridas em outros locais. Pelo fato de entender que o problema é consequência de algo que deve ser aceito, pois é daquela atividade que se retira o 
sustento, a renda etc., ao analisar o problema pelo prisma da "relação custobenefício", a pessoa ou grupo acaba aceitando a injustiça e não lutando contra ela.

Exemplo marcante se encontra na ampla utilização de agrotóxicos no Brasil. Apesar de existirem denúncias e campanhas, como a Campanha Nacional contra os agrotóxicos e pela vida (www.contraosagrotoxicos.org), muitos agricultores utilizam esses produtos sem questionar os efeitos agudos e crônicos de seu uso. $O$ imaginário de que os agrotóxicos não são perigosos ou não fazem mal à saúde leva a sua aceitação e, inclusive, à despreocupação em relação aos procedimentos adequados de uso e manejo desses produtos e de equipamentos de proteção individual (EPI) nos momentos de aplicação e após as aplicações (lavagem de equipamentos e roupas). Muitas vezes, somente quando algum membro da família é intoxicado, desperta-se para a preocupação com o uso e a exposição aos agrotóxicos.

4) Injustiças implícitas e ocultadas, não geradoras de mobilizações e/ou conflitos

Nesses casos, a população afetada por determinada obra, atividade ou consequência da atividade, não a percebe enquanto uma geradora de injustiça ambiental, nem sente seus efeitos negativos. Mesmo podendo haver narrativas contrárias, elas geralmente são ocultadas, enquanto os aspectos "positivos" são evidenciados. Esse tipo de injustiça é muito comum, pois pode estar relacionada a diversas atividades econômicas e a atividades laborais precarizadas e impactantes para a saúde humana e o ambiente. Em uma área rural, pode estar ligada ao contato com produtos químicos ou ao trabalho extenuante. Em uma cidade, pode estar ligada ao próprio processo de expansão urbana, através da ocupação de áreas inadequadas, levando a degradação ambiental e a riscos à vida de pessoas pelo fato de viverem em áreas perigosas ou insalubres (encostas, áreas inundáveis etc.). Em indústrias e estabelecimentos comerciais ou de serviços, podem estar relacionadas a condições perigosas de trabalho, ao ruído, odor ou contato com poluentes atmosféricos e hídricos provocados pela atividade.

Geralmente, dissemina-se um imaginário, fundamentado no ideal do desenvolvimento/progresso, do crescimento econômico e, sobretudo, da modernidade, que propaga narrativas que minimizam, ocultam ou até apoiam e naturalizam essas injustiças, fazendo com que, muitas pessoas, além de acreditar nessas narrativas, passam a não acreditar em narrativas que dizem o contrário. 
Trata-se da ideia de um "mal necessário", onde as consequências passam a ser vistas como irrelevantes ou inevitáveis, ou mesmo, como algo positivo. Desta forma, há uma relativização ou descrédito de informações pautadas em evidências empíricas e científicas, e, pior ainda, uma adoção de discursos altamente exploratórios e nefastos.

Esses elementos reforçam a tese de Machado Araoz (2017), a respeito de um processo de naturalização da crise ecológico-civilizatória e de suas catástrofes.

\section{Desconstrução de injustiças ambientais}

De modo geral, pesquisadores, jornalistas, lideranças comunitárias, representantes de ONGs e de outras instituições de defesa de direitos humanos e ambientais, além de outros sujeitos sociais, têm feito denúncias e análises sobre injustiças ambientais. Mas, para além da denúncia e divulgação das injustiças, como contribuir para o processo de desconstrução narrativa e material dessas injustiças?

Alguns exemplos de injustiças explícitas e evidenciadas pela mídia hegemônica, estão nas tragédias (sobretudo, crimes) ligadas ao rompimento das barragens com rejeitos de minérios nos municípios de Mariana e Brumadinho, bem como aos recorrentes movimentos de massa em encostas. Devido à cobertura ampla da mídia no momento de ocorrência desses eventos, essas injustiças se tornam visíveis e conhecidas pela maioria da população, gerando comoção e revolta na maior parte das pessoas. Após as tragédias, no entanto, essas injustiças costumam ser esquecidas, pois com o passar do tempo, novas tragédias surgem, o que enseja dizer que há certa banalização de várias injustiças ambientais.

Mesmo quando divulgadas pela imprensa, muitas injustiças acabam sendo vistas como um "mal necessário" e a luta contra elas pode ser consideradas "coisa de vagabundo", deixando de despertar a indignação e mesmo a sensibilização de muitas pessoas. Outras injustiças podem não chegar ao conhecimento da população através da grande imprensa, como assassinatos de ativistas e trabalhadores, crimes contra grupos de excluídos (ex. incêndio criminoso em acampamento de sem-teto em Curitiba em 2019), perseguições e outras desapropriações/desterritorializações por todo o país.

Infelizmente, outro fato comum, está na distorção das causas e consequências das injustiças ambientais. Os injustiçados costumam ser criminalizados e os opressores e exploradores, ocultados, denotando inversão de papéis e de valores sociais. Atualmente, chega-se ao ponto de se questionar as próprias evidências 
empíricas e científicas sobre as injustiças, através de discursos vagos e falsos. Ideias inimagináveis como a Terra plana e a recente banalização das consequências provocadas pelo vírus Covid-19, pelo Presidente da República e por parte de diversos cidadãos brasileiros, são evidências nesse sentido. Vivemos em tempos de pós-verdade!

Certamente, há necessidade urgente de desconstrução ideológica e material das injustiças. Mas como fazê-la no plano ideológico e concreto?

Conforme comentado, Leff (2017) discute elementos de uma dialética da desconstrução-construção, que serviram como inspiração para o debate proposto a seguir. Algumas reflexões de Leff serão apresentadas, no sentido de fundamentar a discussão dessa parte final do artigo.

A partir do diálogo com povos indígenas, Leff (2017, p. 143), afirma que "[...] no hay emancipación posible que no pase por un proceso de deconstrucción de los modos dominantes de conocimiento y por la reconstrucción, legitimación e institución de otros modos de ser-en-el-mundo". O autor também clama pela desconstrução da racionalidade da modernidade e pela construção de uma racionalidade ambiental e de um mundo efetivamente sustentável ${ }^{8}$, onde a Ecologia Política tem um papel fundamental.

\begin{abstract}
La ecología política es el lugar de encuentro de racionalidades diferenciadas y de un diálogo de saberes, entendido como la práctica de una ontología de la diversidad, una política de la diferencia y una ética de la otredad que trasciende a una dialéctica de contrarios y llama a la deconstrucción y reconstrucción del orden de la racionalidad económica y jurídica de la modernidad (LEFF, 2017, p. 155).
\end{abstract}

A ideia de uma dialética da desconstrução-construção, vai na linha do pensamento de Leff. No entanto, considerando as diversas possibilidades de se abordar processos de desconstrução-construção, o enfoque, neste artigo, será para a desconstrução de injustiças ambientais, sobretudo de narrativas que as apoiam de alguma forma, bem como para a construção de narrativas e práticas insurgentes e emancipatórias, que estão associadas à própria construção do giro descolonial.

Buscando avançar no debate sobre a descolonialidade, Machado Araoz (2017, p. 214-219) discute, além da perspectiva do giro decolonial, outros tipos de mudanças estruturais que se contrapõem ao Projeto da Modernidade/Colonialidade.

\footnotetext{
${ }^{8}$ Apesar de adotar a ideia de sustentabilidade, Leff faz críticas a banalização do conceito de desenvolvimento sustentável e de sustentabilidade. Segundo ele, esses conceitos foram erroneamente utilizados para a manutenção da lógica do capital.
} 
Ao destacar a relevância de uma revolução epistêmico-política, são evidenciadas quatro grandes mudanças paradigmáticas:

1) O giro descolonial, pautado em um processo radical de desconstrução do imaginário desenvolvimentista/progressista;

2) O giro sociometabólico, fundamentado em uma redefinição radical do modo dominante de reprodução da vida social, ou seja, do capitalismo. Através dos dogmas do crescimento e do produtivismo, se propaga a ideia de uma padronização de estilos de vida, formas de consumo, técnicas de produção e organização, se impondo a atual divisão social do trabalho. Uma das principais estratégias do capitalismo, é criar um imaginário social a respeito de que esse sistema é o ideal, superior e inevitável, dando a impressão de que é o único sistema possível. Assim, a superação deste imaginário, ou seja, o giro descolonial, é crucial para a efetivação do giro sociometabólico";

3) O giro biocêntrico, que implica "[...] asumir ontológicamente que somos parte-de-la-Naturaleza", ou seja, de comunidade funcional de vida. Não se trata de um biocentrismo que percebe a natureza enquanto objeto e que nega o ser humano. A respeito da relação indivíduo/comunidade, o giro biocêntrico supõe uma revisão radical do individualismo criado pelo ethos do Capital.

4) O giro despatriarcal, que supõe uma desconstrução radical da matriz patriarcal de relacionamento com a natureza em geral, e entre os sujeitos sociais em particular.

Essas mudanças apontadas por Machado Araoz (2017), envolvem, necessariamente, processos de desconstrução-construção de narrativas e práticas/ações. Os giros descolonial, biocêntrico e despatriarcal dizem respeito a desconstrução de narrativas que historicamente permeiam o imaginário social da grande parte da sociedade latino-americana. A adoção das ideias de modernidade, desenvolvimento e progresso, entendidos, sobretudo, enquanto algo atingível através do produtivismo, do consumismo e do crescimento econômico, se tornaram, para muitos, a principal finalidade de nossa existência. Já a ideia de separação do ser humano em relação à natureza, ao se perceber a natureza enquanto objeto e 0

\footnotetext{
${ }^{9} \mathrm{O}$ "[...] cambio sociometabólico no implica "aumentar los ingresos" y/o "redistribuir la riqueza", sino redefinir radicalmente el sentido social de la riqueza en función de los valores de uso y, sí, distribuir los medios de subsistencia de modo equitativo a fin de garantizar la vida a nivel de cada individuo, cada grupo social, integralmente" (p. 216-217).
} 
ser humano enquanto sujeito, assim como o individualismo e a competição enquanto algo natural (darwinismo social), embasam o antropocentrismo, fazendo com que as demais formas de vida sejam consideradas algo que podemos usar como quisermos. Por fim, a centralidade do patriarcalismo, apesar do crescimento dos movimentos feministas e LGBT, também é uma marca social a ser desconstruída no contexto da revolução epistêmico-política proposta.

Em relação ao plano material, o giro sociometabólico pressupõe novas ações para a reprodução da vida social, materializadas em algo que poderia ser denominado pós-capitalismo. Nesse sentido, existem práticas que têm sido executadas, adaptadas e multiplicadas, que valorizam o que Machado Araoz (2020) chama de geosociometabolismo. Algumas delas, como a agroecologia, são rapidamente mencionadas na próxima seção deste artigo.

Sem dúvida, o processo de desconstrução das injustiças ambientais não é tarefa simples, haja vista que os responsáveis pelas injustiças possuem poder econômico e contam com o apoio da grande mídia e, muitas vezes, de representantes do próprio Estado, sobretudo políticos. Contudo, a seguir, expõem-se algumas questões para a reflexão dos leitores e, de forma propositiva, alguns caminhos que podem contribuir nesse processo de desconstrução de narrativas que apoiam injustiças ambientais. Cabe ressaltar, que a intenção é, simplesmente, externalizar algumas preocupações do autor sobre possíveis formas de ação direta, que contribuam para a sensibilização social a respeito da importância do ambiente, e consequentemente, para o difícil processo de transformação social e de transformações na relação com outros seres vivos, com os ecossistemas e, de forma mais ampla, com o espaço geográfico.

Como ampliar a sensibilização da opinião pública em relação às injustiças ambientais e aos falsos discursos predominantes?

Entende-se que é preciso:

- Conhecer e expor quem são os prejudicados (injustiçados) mas também quem são os beneficiados com as injustiças;

- Entender e expor as contradições das narrativas, dos discursos daqueles que ocultam, minimizam, distorcem ou ignoram as injustiças ambientais, ou seja, dos responsáveis e de seus comparsas e defensores;

- Conhecer e expor os efeitos sociais e ambientais deletérios das injustiças. 
Quais as instituições que podem ser parceiras dos injustiçados nesse processo? (Ministério Público? Órgãos da imprensa comprometidos com os excluídos? ativistas? pesquisadores? ONGs?).

Que formas de denúncia, divulgação e mobilização têm sido eficazes? Como potencializá-las?

Como sensibilizar e mobilizar as pessoas para lutas contra injustiças ambientais?

Conforme já apontado, a desconstrução de injustiças, necessita, para além da denúncia e da crítica, da proposição de alternativas insurgentes, emancipatórias e descoloniais (ou anticoloniais - SOUZA, 2019a). Ao apontar possíveis caminhos nesse sentido, mesmo que sua efetivação seja difícil e complexa, contribui-se no processo de desconstrução das injustiças, pois são vislumbrados novos horizontes, novas possibilidades. Não obstante, a desconstrução perpassa a demonstração de que é possível construir outras formas de se relacionar com a natureza e com as pessoas, do mesmo modo que a construção de alternativas, se pauta no questionamento e no combate da racionalidade responsável pelas injustiças. É nesse contexto que se optou por clamar por uma dialética da desconstruçãoconstrução, com base no pensamento de Enrique Leff (2017).

\section{Construção de alternativas descoloniais}

Da mesma forma que é pertinente desconstruir determinadas narrativas que minimizam, naturalizam ou justificam injustiças ambientais, entende-se que é preciso identificar, conhecer, analisar e fortalecer o processo de construção de alternativas que contribuam para a justiça ambiental. Identificar, conhecer e analisar, são papéis de pesquisadores da área da Ecologia Política, mas também de outros sujeitos interessados. Para identificar, conhecer, analisar e desconstruir as injustiças ambientais, o diálogo e a interação de pesquisadores com os injustiçados são fundamentais para se construir análises e estratégias de ação.

Alguns valores sociais são básicos nesse sentido, como o respeito ao próximo e aos elementos e dinâmicas da natureza; a solidariedade e a cooperação; o reconhecimento da interdependência entre o mundo não-vivo (abiótico) e os seres vivos, a valorização da liberdade, entre outros. No contexto das alternativas que estão pautadas nesses valores, destacam-se as seguintes: 
- Agroecologia, agroflorestas, permacultura e outras práticas de uso de elementos naturogênicos;

- Gestão não hierárquica e autonomista de povos e comunidades (autonomia individual e coletiva) (SOUZA, 2017);

- Protagonismo das mulheres, jovens e povos de diversas etnias, sobretudo os povos originários e as chamadas populações tradicionais;

- Potencialização de simbioses na relação sociedade-natureza.

Mas como fortalecer essas experiências de construção de alternativas?

No tocante ao trabalho de pesquisa, seguem algumas sugestões:

1) identificar experiências que se apresentam como alternativas descoloniais;

2) conhecer essas experiências e os sujeitos envolvidos, considerando seus objetivos, ações, relações de cooperação e conflito, avanços e obstáculos;

3) analisar as alternativas a partir de teorias e conceitos atinentes à Ecologia Política e às diversas áreas de conhecimento vinculadas;

4) discutir os resultados das análises com os sujeitos envolvidos nas alternativas, ouvindo suas opiniões sobre os objetivos, metodologia e resultados obtidos.

No plano da extensão e do ativismo (ação), faz-se necessário estabelecer narrativas positivas e convincentes, pautadas em evidências empíricas e científicas. Essas narrativas também devem ser traduzidas em materiais atraentes às pessoas, como vídeos, animações, músicas etc.

Um papel importante de ativistas, extensionistas e militantes em geral, que acreditam na possibilidade de transformação social, é contribuir para a construção de narrativas que divulguem as experiências exitosas, no sentido de mostrar que existem outras possibilidades pautadas em valores para além da modernidade, do desenvolvimento e do crescimento econômico, refletindo e agindo na criação de formas de comunicação, que sensibilizem as pessoas para as alternativas existentes e para a viabilidade de sua replicação.

Nesse processo de identificação e discussão dos avanços e obstáculos, a autocrítica de pesquisadores, ativistas, injustiçados e outros sujeitos envolvidos, é muito importante. Sem autocrítica, fica difícil identificar como superar as adversidades. Da mesma forma, é preciso estar atento às diversas relações de poder existentes, inclusive entre os sujeitos injustiçados. Infelizmente, pode haver 
processos de concentração do poder e de tomada de decisões, cooptação e injustiças internas entre os próprios injustiçados.

Todas essas ações, seja no plano da desconstrução ou da construção, devem ser repensadas constantemente, para identificação de lacunas, novas possibilidades, erros etc. Trata-se de um processo de construção contínuo, que deve ser franco e bem organizado. Isso envolve, também, politização em sentido crítico e combate às mais diversas hierarquias sociais existentes.

\section{Considerações finais}

Este artigo procurou apresentar alguns pressupostos da Ecologia Política, com destaque para uma Ecologia Política latino-americana, em que os pobres e excluídos têm sido alvo das mais variadas injustiças ambientais. Por outro lado, vários desses pobres, organizados ou não, têm protagonizado resistências, mobilizações e lutas por justiça ambiental.

O artigo foi desenvolvido, partindo do pressuposto de que há dialética entre injustiças ambientais e o movimento por justiça ambiental, assim como entre o necessário processo de desconstrução das injustiças e de construção de alternativas emancipatórias e descoloniais, tendo como base a questão dos discursos e narrativas, mas levando em consideração, que também existe uma dialética entre o simbólico/imaginário e o material.

Além das análises de pesquisadores e de outros profissionais, a construção de alternativas descoloniais demanda ações militantes (atuação enquanto cidadãos) no contexto dessas alternativas. Essas ações podem estar ligadas a ativismos ou a outras formas de insurgência, e podem ser executadas por qualquer cidadão: um pesquisador; um atingido por determinada injustiça; um trabalhador de qualquer área ou um excluído/injustiçado.

Dado que os pesquisadores ligados à Ecologia Política possuem, de alguma forma, algum tipo de relação com as populações injustiçadas, cabe refletir sobre como o pesquisador pode contribuir para além de sua atuação profissional. Sabedores de que existem diversas opiniões a respeito desse assunto, entende-se que a opção por ser, além de pesquisador, ativista ou militante, é algo pessoal.

Todavia, em um contexto histórico onde ativismos e lutas por direitos - dos e pelos mais pobres - têm sido questionados, criticados e até criminalizados, a resistência social no combate às injustiças ambientais é desafiadora, porém necessária. 


\section{Referências}

ACSELRAD, Henri. Ambientalização das lutas sociais - o caso do movimento por justiça ambiental. Estudos avançados, v. 24, n. 68, pp. 103-119, 2010.

ALIMONDA, Héctor. La colonialidad de la naturaleza: Una aproximación a la Ecología Política latinoamericana. In: ALIMONDA, H (org.). La naturaleza colonizada: ecología política y minería en América Latina. Buenos Aires: CLACSO, 2011, p. 21-58.

ALIMONDA, Héctor. Ecología política latinoamericana y pensamiento crítico: vanguardias arraigadas. Desenvolvimento e meio ambiente, 35, pp. 161-168, 2015. DOI: 10.5380/dma.v35i0.44557

ALIMONDA, Héctor. Notas sobre la ecología política latinoamericana: arraigo, herencias, diálogos. Ecología Política, v.51, pp. 36-42, 2016.

ALIMONDA, Héctor. En clave de Sur: la ecología política latinoamericana y el pensamiento crítico. In: ALIMONDA, Hector; PÉREZ, C.; MARTÍN, F. (orgs.). Ecología política latinoamericana: pensamiento crítico, diferencia latinoamericana y rearticulación epistémica. CLACSO; México/Ciccus. Vol I., 2017, p. 33-50.

ALIMONDA, Héctor; PÉREZ, Catalina; MARTíN, Facundo (orgs.). Ecología política latinoamericana: pensamiento crítico, diferencia latinoamericana y rearticulación epistémica. CLACSO; México/Ciccus. Vol I., 2017a.

ALIMONDA, Héctor; PÉREZ, Catalina; MARTíN, Facundo (orgs.). Ecología política latinoamericana: pensamiento crítico, diferencia latinoamericana y rearticulación epistémica. CLACSO; México/Ciccus. Vol II., 2017b.

BAILEY, Sinéad; BRYANT, Raymond. Third world political ecology. London and New York: Routledge, 2005.

BACHRACH, Peter; BARATZ, Morton S. Duas faces do poder. Revista de Sociologia Política, v. 19, n. 40, p. 149-157, (2011[1962]).

BATTERBURY, Simon. Doing political ecology inside and outside the academy. In: BRYANT, Raymond (Ed.). The international handbook of political ecology. Edward Elbar Publishing: Cheltenham, UK + Northampton, MA, USA, 2015. p. 27-43.

BLAIKIE, Piers. Environment and access to resources in Africa, Africa, 59, 18-40, 1989.

ESCOBAR, Arturo. Depois da natureza - Passos para uma ecologia Política antiessencialista. In: PARREIRA, Clélia; ALIMONDA, Héctor (orgs.). Políticas Públicas Ambientáis Latinoamericanas, Brasilia: abaré/FlaCso, 2005.

ESCOBAR, Arturo. Ecología Política de la globalidad y la diferencia Arturo Escobar. In: ALIMONDA, H (org.). La naturaleza colonizada: ecología política y minería en América Latina. Buenos Aires: CLACSO, 2011, p. 61-91.

GÓMEZ, Max. Una aproximación a las contribuciones de Arturo Escobar a la ecología política. Ecología Política, n. 50, pp. 100-105, 2015.

HARVEY, David. The nature of environment: the dialectics of social and environmental change. In: Miliband. R.; Panitch, L. (Org.). Real Problems, False Solutions: Socialist Register. Merlin Press: London, pp. 1-51, 1993. 
KOTHARI, Ashish; SALLEH, Ariel; ESCOBAR, Arturo; DEMARIA, Federico; ACOSTA, Alberto. (Eds.). Pluriverse: a post-development dictionary. India: Tulika Books, 2019.

LEFF, Enrique. Encountering political ecology: epistemology and emancipation. BRYANT, Raymond (Ed.). The international handbook of political ecology. Edward Elbar Publishing: Cheltenham, UK + Northampton, MA, USA, 2015. p. 44-56.

LEFF, Enrique. Las relaciones de poder del conocimiento en el campo de la ecología política: una mirada desde el sur. In: ALIMONDA, Héctor; PÉREZ, Catalina; MARTÍN, Facundo (orgs.). Ecología política latinoamericana: pensamiento crítico, diferencia latinoamericana y rearticulación epistémica. CLACSO; México/Ciccus. Vol I., 2017, p. 129-165.

MACHADO ARAOZ, Horacio. "América Latina" y la ecología política del sur. luchas de reexistencia, revolución epistémica y migración civilizatoria. In: ALIMONDA, Héctor; PÉREZ, Catalina; MARTíN, Facundo (orgs.). Ecología política latinoamericana: pensamiento crítico, diferencia latinoamericana y rearticulación epistémica. CLACSO; México/Ciccus. Vol II., 2017, p. 193-224.

MACHADO ARAOZ, Horacio. La minería colonial y las raíces del Capitaloceno: Habitus extractivista y mineralización de la condición humana. AMBIENTES: Revista de Geografia e Ecologia Política, v. 2, n. 1., pp. 65-97, 2020.

MARTINEZ-ALIER, Joan. O ecologismo dos pobres: conflitos ambientais e linguagens de valoração. Contexto, 2015a.

MARTINEZ-ALIER, Joan. La ecología política y el movimiento global de justicia ambiental. Ecología política, n. 50, pp. 56-61, 2015b.

MARTINEZ-ALIER, Joan. Environmental Justice. In: KOTHARI, Ashish; SALLEH, Ariel; ESCOBAR, Arturo; DEMARIA, Federico; ACOSTA, Alberto. (Eds.). Pluriverse: a postdevelopment dictionary. India: Tulika Books, 2019, p. 182-184.

MERLINSKY, Gabriela. Los movimientos de justicia ambiental y la defensa de lo común en américa latina. Cinco tesis en elaboración. In: ALIMONDA, Hector; PÉREZ, Catalina; MARTÍN, Facundo (orgs.). Ecología política latinoamericana: pensamiento crítico, diferencia latinoamericana y rearticulación epistémica. CLACSO; México/Ciccus. Vol II., 2017, p. 241-264.

MOREANO, Melissa; MOLINA, Francisco; BRYANT, Raymond. Hacia una ecología política global: aportes desde el sur. In: ALIMONDA, Hector; PÉREZ, C.; MARTíN, F. (Org.). Ecología política latinoamericana: pensamiento crítico, diferencia latinoamericana y rearticulación epistémica. CLACSO; México/Ciccus. Vol I., 2017, p. 197-211.

PORTO-GONÇALVES, Carlos W.; LEFF, Enrique. Political Ecology in Latin America: the Social Re-Appropriation of Nature, the Reinvention of Territories and the Construction of an Environmental Rationality. Desenvolvimento e meio ambiente, 35, pp. 65-88, 2015. DOI: 10.5380/dma.v35i0.43543

PORTO-GONÇALVES. Carlos Walter. A globalização da natureza e a natureza da globalização. Rio de Janeiro: Civilização Brasileira, 2006.

QUIJANO, Aníbal. Colonialidade do poder, eurocentrismo e América Latina. In: LANDER, Edgardo (org.). A colonialidade do saber: eurocentrismo e ciências sociais. Perspectivas latino-americanas. CLACSO, Buenos Aires, Argentina, 2005, p. 107-130. 
RAFFESTIN, Claude. Por uma Geografia do Poder. São Paulo: Ática, 1993.

ROMERO, Adela P. ¿Por qué pensar un giro decolonial en el análisis de los conflictos socioambientales en América Latina?. Ecología política, n. 51, pp. 15-20, 2016.

SANTOS, Milton. A natureza do espaço. São Paulo: HUCITEC, 1996.

SOUSA SANTOS. Boaventura de. Construindo as Epistemologias do Sul. Antologia. Vol II. Buenos Aires: CLACSO, 2018.

SOUZA, Marcelo L. de. "Espaciologia": Uma Objeção (Crítica aos Prestigiamentos PseudoCríticos do Espaço Social). Terra Livre, v. 10, p. 21-45, 1988.

SOUZA, Marcelo L. de. Os conceitos fundamentais da pesquisa sócio-espacial. Rio de Janeiro: Bertrand Brasil, 2013.

SOUZA, Marcelo L de. Por uma geografia libertária. Rio de Janeiro: Consequência, 2017.

SOUZA, Marcelo L. de. Quando o trunfo se revela um fardo: reexaminando os percalços de um campo disciplinar que se pretendeu uma ponte entre o conhecimento da natureza e o da sociedade. Geousp - Espaço e Tempo, v. 22, n. 2, pp. 274-308, 2018.

SOUZA, Marcelo L. de. Ambientes e Territórios: Uma introdução à Ecologia Política. Rio de Janeiro: Bertrand Brasil, 2019a.

SOUZA, Marcelo L. de. O que é a Geografia Ambiental? AMBIENTES: Revista de Geografia e Ecologia Política, v. 1, n. 1., pp. 14-37, $2019 \mathrm{~b}$.

SVAMPA, Maristela. "Consenso de los Commodities" y lenguajes de valoración en América Latina”. Nueva Sociedad, 244, pp. 30-45, 2013.

\section{NOTAS DE AUTOR}

\section{CONTRIBUIÇÃO DE AUTORIA}

Luciano Zanetti Pessôa Candiotto - Concepção. Elaboração do manuscrito, revisão e aprovação da versão final do trabalho.

\section{FINANCIAMENTO}

Não se aplica

\section{CONSENTIMENTO DE USO DE IMAGEM}

Não se aplica

\section{APROVAÇÃO DE COMITÊ DE ÉTICA EM PESQUISA}

Não se aplica

\section{CONFLITO DE INTERESSES}

Não se aplica

\section{LICENÇA DE USO}

Este artigo está licenciado sob a Licença Creative Commons CC-BY. Com essa licença você pode compartilhar, adaptar, criar para qualquer fim, desde que atribua a autoria da obra.

\section{HISTÓRICO}

Recebido em: 02-12-2019

Aprovado em: 06-10-2020 